\title{
How do spatial and environmental factors affect the fish community structure in seasonally flooded karst systems?
}

\author{
Joel Loera-Pérez ${ }^{1,2}$, José L. Hernández-Stefanoni ${ }^{3}$ \& Xavier Chiappa-Carrara ${ }^{4,5}$ \\ ${ }^{1}$ Posgrado en Ciencias del Mar y Limnología, Universidad Nacional Autónoma de México (UNAM) \\ México D.F., México \\ ${ }^{2}$ Area de Recursos Naturales, Departamento de Suelos, Universidad Autónoma Chapingo \\ Chapingo, México \\ ${ }^{3}$ Unidad de Recursos Naturales, Centro de Investigación Científica de Yucatán (CICY) A.C., México \\ ${ }^{4}$ Facultad de Ciencias, Universidad Nacional Autónoma de México, Mérida, Yucatán, México \\ ${ }^{5}$ Escuela Nacional de Estudios Superiores, Unidad Mérida, UNAM, México \\ Corresponding author: Joel Loera-Pérez (jloerap@ chapingo.mx)
}

\begin{abstract}
Spatial and temporal variation of the physical and chemical conditions of coastal karst wetland ecosystems, which annually range from flooded to completely dry, generate a very dynamic fish community structure. We assessed the relative influence of spatial dependence and environmental factors on fish community structure in a seasonally flooded tropical karst system on the north-western coast of the Yucatan Peninsula, Mexico. Sampling was carried out between November 2009 and April 2010, while the area was inundated by seasonal floodwater. Fish biomass, abundance and species richness, as well as environmental variables and geographic location, were recorded. A variation partitioning analysis was performed to assess the influence of the spatial and environmental variables on the fish community using multiple regression, and a principal coordinates analysis of neighbor matrices (PCNM). Spatial factors had a greater influence on the changes in the community structure than the environmental factors. After spatial variation, environmental effects from conductivity, oxygen saturation, temperature and depth further shaped the community. These results imply that, despite the diversity of niches and wide variation in environmental conditions, the structuring force of the community is the spatial dynamic probably linked to species dispersal mechanisms and reproductive strategies.
\end{abstract}

Keywords: Gambusia yucatana; wetland ecosystem; spatial analysis; Yucatan Peninsula

\section{INTRODUCTION}

Karstic coastal habitats of the Caribbean basin are highly dynamic environments distinguished by the contrast between rainy and dry season, which results in high variability of the physical, chemical and ecological conditions (Ortega-Mayagoitia et al., 2002; De Angelis et al., 2010; Escalera-Vázquez \& Zambrano, 2010; Gaiser et al., 2015). Seasonal changes in the flooded area of these habitats may be the primary challenge they present for aquatic life. Changes in the extent and depth of water bodies determine not only space availability for the fish community, but the accessibility to other resources of the environment
(Baber et al., 2002; Ruetz et al., 2005). Two groups of variables have been identified to classify the primary controls of communities in landscapes. The first includes environmental factors, which are spatially structured and are responsible for the distribution of species through species-habitat associations (Legendre, 1993). The second group, formed by space-dependent variables, is commonly associated with the dispersal of individuals and the overdispersion of populations (Cottenie, 2005). The spatial organization of fish communities is influenced by these variables based on the observation that neighboring sites generally display similar abundance, biomass and species richness than distant sites (Morlon et al., 2008). Hence, analysis of

Corresponding editor: Yassir Torres 
the structure of fish communities must consider the effect of environmental and spatial factors (Legendre \& Fortin, 1989; Legendre, 1993). In dynamic ecosystems, another essential element to consider is the time between disturbances. Community responses to seasonality and their time to recover from seasonal droughts are fundamentally linked to the physical, chemical, depth, area and volume of the habitats experienced by aquatic animals in Caribbean karstic regions (Trexler et al., 2001; Baber et al., 2002).

Various models have been proposed to explain the factors regulating the structure and dynamics of fish communities (Nuñez-Lara et al., 2012). Some of them describe communities as stable biological systems regulated by competition or predation (Sale, 1980; Soto-Ortiz, 2015). Others have suggested that there is no such balance, but rather spatial and temporal variation influenced mainly by stochastic processes, such as larval recruitment (Doherty, 1991; Carr \& Syms, 2006). Other authors have suggested a complementary effect from recruitment and postrecruitment processes, which includes a response to habitat, environmental factors, and biological interactions (Sale \& Douglas, 1984; Choat \& Bellwood, 1985; Menge et al., 2011). It is now known that diverse factors and processes, both stochastic and deterministic, govern fish community structure and that these strictly depend on the spatial scale of observation (Waltho \& Kolasa, 1996; Alexander et al., 2012). Aquatic ecologists are beginning to appreciate that processes on multiple scales shape the patterns they observe at local site-scales, which might be the reason why there is a growing interest to evaluate the relative influence of spatial dependence and environmental factors on the structure and composition of biological communities (Jones et al., 2008).

Nonetheless, there are different arguments to explain variation in the structure of a community (Condit et al., 2002; Tuomisto et al., 2003). Among others, the niche theory (Hutchinson, 1957; Leibold, 2008) states that the structure of a community is mainly determined by the variability of environmental factors. Therefore, abundance is an indicator of the suitability of environmental factors for the survival, growth and reproduction of the population. On the other hand, the neutral theory states that all species are competitively equal and capable of coping with a range of environmental factors and that species composition varies in response to dispersal limitation. Finally, the mass-effect model states that dispersal and environmental heterogeneity interact to determine community structure (Condit et al., 2002). Therefore, it is of great interest to understand the relative contribution of processes related to environmental heterogeneity and dispersal limitation (López-Martínez et al., 2013).
This research aims to analyze the extent to which environmental factors and spatial dependence are correlated with variation of fish community structure in temporarily flooded karst in the Yucatan State, Mexico. Similar ecosystems are found throughout the Caribbean basin and beyond but are little studied (Schwartz \& Jenkins, 2000). Seasonally flooded karst systems provide excellent models to consider how rapidly varying and contrasting conditions affect community structure through the interaction of species traits, environmental variables, and spatial habitat structure.

\section{MATERIALS AND METHODS}

\section{Study area}

Karst landscapes are found worldwide and formed from the dissolution of soluble rocks such as limestone, dolomite and gypsum. Karstic ecosystems are characterized by underground drainage systems with solution holes, sinkholes and caves (Lace \& Mylroie, 2013). The study area is a karstic coastal wetland of $26.3 \mathrm{~km}^{2}$ in the natural protected area of El Palmar on the northwestern Yucatan Peninsula, Mexico (Fig. 1). The area is flat, and it is flooded during the local rainy season (June to October); there are small permanent freshwater springs in the landscape that serve as dry-season refuges for fish. Water levels rise in the rainy season, flooding these small systems, increasing connectivity and permitting fish to enter the rest of the system.

The average annual temperature is $26.5^{\circ} \mathrm{C}$; total annual rainfall generally ranges between $700-800 \mathrm{~mm}$, concentrated between June and October, with the dry season extending from March to May. The dry season is characterized by precipitation between $0-30 \mathrm{~mm}$ and temperatures in the range of $36-38^{\circ} \mathrm{C}$. September is the rainiest month, with an average of $125 \mathrm{~mm}$. There is also a transitional period between these two seasons, from November to February, distinguished by the influence of cold winds accompanied by low atmospheric pressures ('Nortes' season). The average temperature of this period is $23^{\circ} \mathrm{C}$, and the mean rainfall is around $40 \mathrm{~mm}$ monthly (UADY, 1999).

\section{Environmental data}

Field data were recorded monthly from November 2009 to April 2010 while the wetland remained flooded, and the fish were residing in small pools that serve as the main source of fish in the area. The study area was divided into 45 hexagons of $340 \mathrm{~m}$ radius, and 40 hexagons were randomly selected once a month, ensuring that every hexagon had the same chance of being sampled each time (Fourqurean \& Rutten, 2003). One sampling site within each hexagon was also ran- 


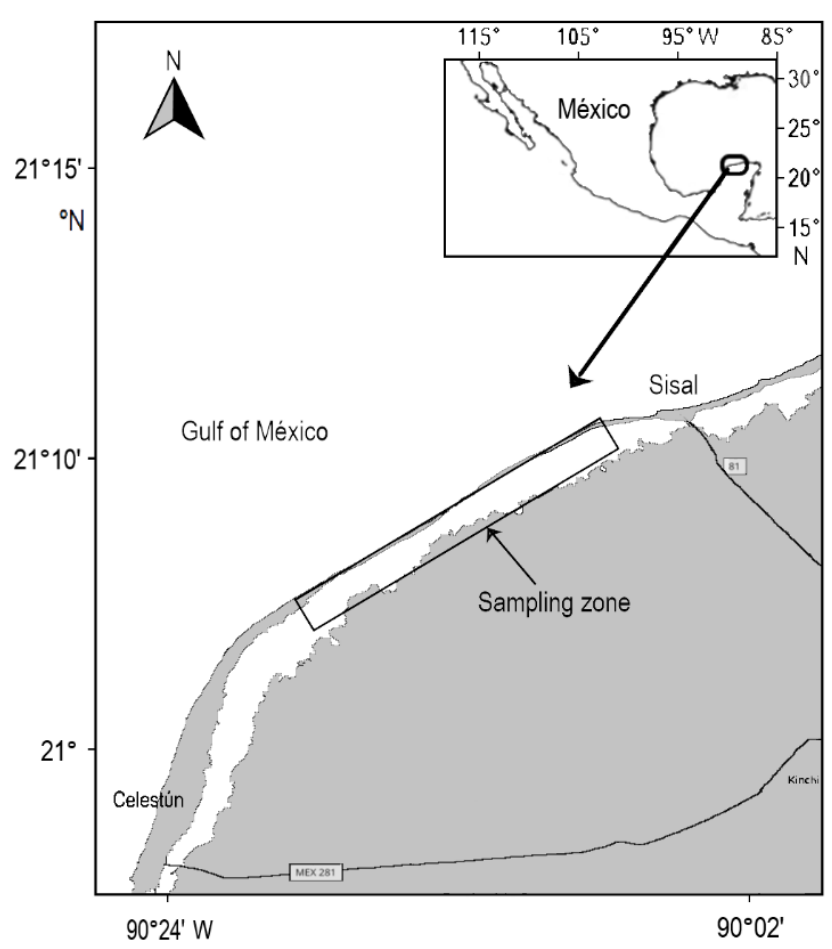

Figure 1. The study area within "El Palmar" State Reserve in Yucatan, México.

domly located every month, recording its geographical position with a Garmin eTrex 20 GPS.

The final sample size was 142 sites distributed as follows: 37 sites were sampled in November, 31 in December, 28 in January, 8 in February (inclement wind conditions prevented effective sampling, no fish samples were taken), 25 sites in March, and 13 sites in April (the onset of the dry season exposed much of the wetland). Fish were caught in a Gee ${ }^{\circledR}$ collapsible minnow trap $(2 \mathrm{~mm}$ mesh and a funnel entrance diameter of $50 \mathrm{~mm}$ ), according to records of the area it is unlikely to find larger fish (Vega-Cendejas, 2005; Gallardo-Torres et al., 2014). Traps were left out in each sampling station for two hours following recommendations by Obaza et al. (2011). Standard length $(\mathrm{SL} \pm 0.1 \mathrm{~cm})$ and wet weight $(\mathrm{W} \pm 0.01 \mathrm{~g})$ of all captured fish were measured with a caliper and a digital electronic balance (Ohaus).

Fishes were identified to species using specialized taxonomic keys for southeastern Mexico and Central America (Greenfield \& Thomerson, 1997; SchmitterSoto, 1998). The number of fish species captured at each sampling site was used as a measure of species richness. Abundance and biomass were subsequently expressed as catch-per-unit-effort (CPUE) (Kobza et al., 2004).

Concurrent with fish sampling, the following environmental variables were measured every month at each sampling site with a Portable YSI EC300 (YSI Inc., Yellow Springs, OH, USA): specific conductivity $\left(\mathrm{mS} \mathrm{cm}^{-1}\right)$, oxygen saturation $(\%)$, temperature $\left({ }^{\circ} \mathrm{C}\right), \mathrm{pH}$ and depth $(\mathrm{m})$. Precipitation data were obtained from the meteorological station located at $21^{\circ} 09^{\prime} 47^{\prime \prime} \mathrm{N}$, $90^{\circ} 02^{\prime} 53^{\prime \prime} \mathrm{W}$ (Managed by National Weather System).

\section{Statistical analysis}

Principal coordinates of neighbor matrices analysis (PCNM, Borcard et al., 2004) is a tool for identifying relationships of ecological descriptors (diversity, biomass and abundance of the fish community) and environmental factors by first identifying significant spatial structure in the ecological descriptor and second relating the form of these specific spatial structures to environmental factors (Borcard et al., 2004).

A set of spatial variables was generated for each month in the studied area, using the PCNM analysis as well as the geographical coordinates of the sampling sites of every month (Fig. 2). The PCNM vectors (spatial variables) represent the spatial structure or spatial dependence among the sampling sites. These variables are the spectral decomposition of the spatial relationships among the study sites, considering not only the separation distance among sites but also their spatial associations (Borcard et al., 2004). The PCNM vectors are uncorrelated variables that can be used as predictors in regression analysis to describe spatial relationships in community data because they are not subject to multicollinearity problems (Borcard \& Legendre, 2002).

The set of explanatory spatial variables, for every one of the months considered in this study, was obtained as follows:

a) Calculation of a Euclidean distance matrix (consisting of geographical distances between site locations),

b) Modification of the Euclidean distance matrix by replacing distances greater than the minimum needed for all sites to remain connected within a network with an arbitrarily large number, as suggested by Borcard et al. (2004) (this was done to retain the distances between the neighboring sites),

c) Principal coordinates analysis (PCO) on the modified distance matrix, which returns the PCNM variables that explain the spatial dependence of fish communities across all spatial scales, and

d) Retention of the principal coordinates axes that correspond to positive and significant eigenvalues.

The set of explanatory PCNM variables was obtained with the PCNM function from the R software SpacemakeR library (Dray et al., 2006). The PCNM analysis produced 21, 20,19, 15 and 3 eigenvectors 

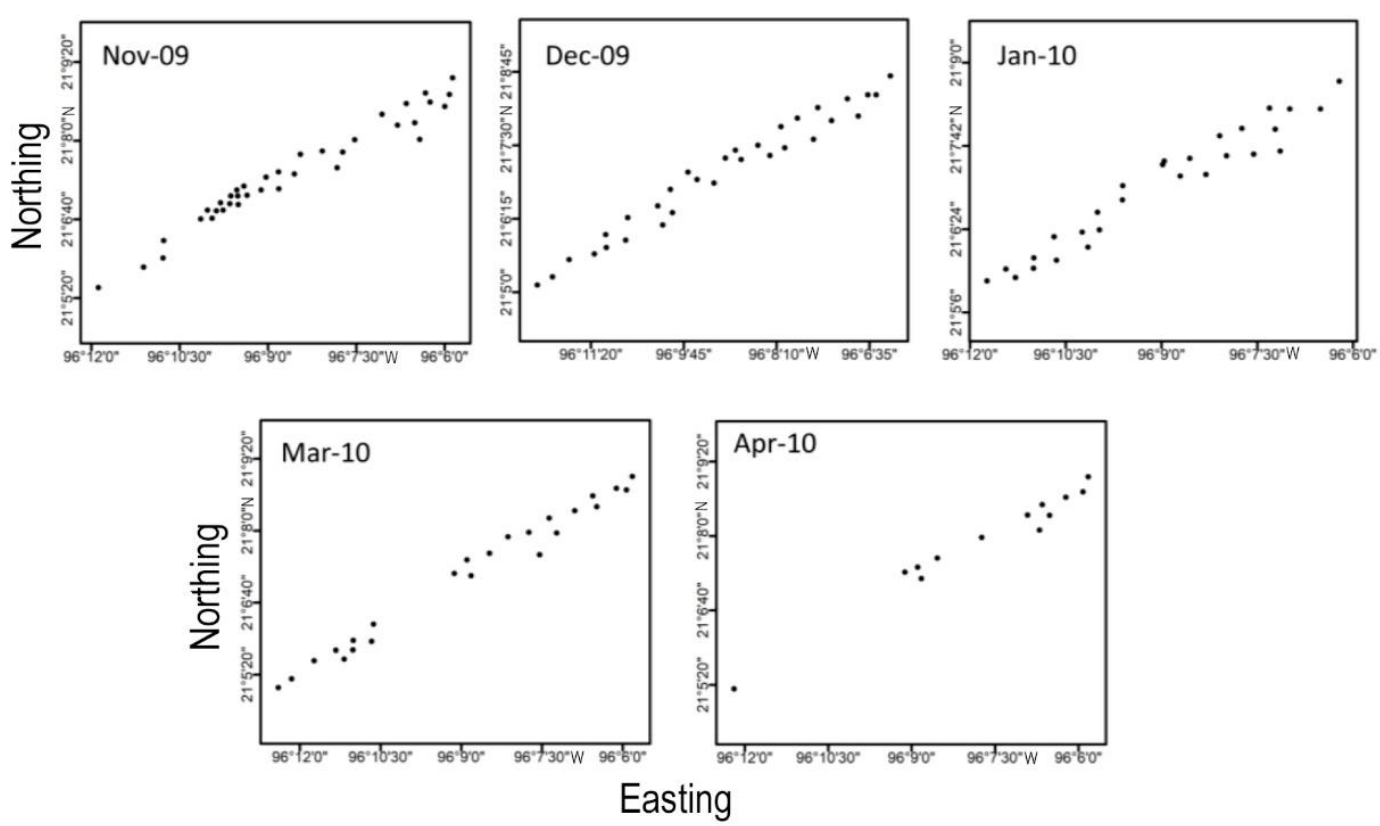

Figure 2. Spatial distribution of the sampled sites for November 2009, December 2009, January 2010, March 2010 and April 2010.

(PCNM vectors), among which 5, 9, 6, 3 and 1 eigenvector, obtained for November, December, January, March and April data, respectively, had positive values and a significant autocorrelation $(P>$ 0.001 ) tested by Moran's I (Borcard et al., 2004). Hence, only these positive and significant vectors were used in the analyses.

We assessed differences in average abundance, biomass and species richness among months using oneway ANOVA and Tukey's test for post-hoc comparisons. Biomass and abundance were transformed $\left(\log _{10} \mathrm{X}\right.$, or $\left.\log _{10} \mathrm{x}+1\right)$ to meet the assumptions of normality and homogeneity of variances (Zar, 1999).

Multiple regression and variance partitioning methods described above were used to quantify the effects of environmental (dissolved and oxygen saturation, temperature, conductivity, $\mathrm{pH}$ and depth) and spatial dependence (PCNM vectors) on abundance, biomass and species richness of fish for every month of the study. First, a model based on environmental variables was fitted to the response variables by multiple regression analysis. This model represents the variability explained by environmental data, and the variation explained jointly by environmental data and spatial structure ( $\left.V_{\text {env }}+S_{\text {env-spat }}\right)$. Response variables (abundance, biomass and species richness) were formally tested for normality and homogeneity of variances in the residuals (Zar, 1999). Secondly, a model based on spatial variables (significant PCNM vectors) was fitted to the response variables by multiple regression analysis. This second model represents spatially dependent variation, plus the variation explained jointly by environmental and spatial structure data $\left(V_{\text {spat }}+S_{\text {env-spat }}\right)$. Thirdly, the total amount of variation explained $\left(V_{\text {env }}+V_{\text {spat }}+S_{\text {env-spat }}\right)$ was calculated by combining the two previous multiple regression models into an overall regression model using exclusively significant selected variables. Both regression analyses used forward selection. Finally, variation partitioning determined the relative importance of exclusively environmental variation $\left[V_{\text {env }}=\left(V_{\text {env }}+V_{\text {spat }}+S_{\text {env-spat }}\right)-\left(V_{\text {spat }}+S_{\text {env-spat }}\right)\right]$, exclusively spatial variation $\left[V_{\text {spat }}=\left(V_{\text {env }}+V_{\text {spat }}+S_{\text {env- }}\right.\right.$ spat $\left.)-\left(V_{\text {spat }}+S_{\text {env-spat }}\right)\right]$, and shared variation $\left[S_{\text {env-spat }}=\right.$ $\left.\left(V_{\text {env }}+V_{\text {spat }}+S_{\text {env-spat }}\right)-\left(V_{\text {env }}\right)-\left(V_{\text {spat }}\right)\right]$ on abundance, biomass and species richness of fish (Borcard et al., 2004) (see Fig. 3).

\section{RESULTS}

Precipitation was highest at the end of October 2009. As a consequence, the maximum depth values in the studied system were registered in November 2009, with an average of $0.5 \pm 0.08 \mathrm{~m}$ (Fig. 4a). The wetland began to evaporate in December, decreasing in-depth and areal extent. Changes occurred in the rest of the parameters measured owing to the reduction in the water body volume. Conductivity gradually increased through the study; it was lowest in December-January with an average of $22.6 \mathrm{mS} \mathrm{cm}^{-1}$, and highest in April, 


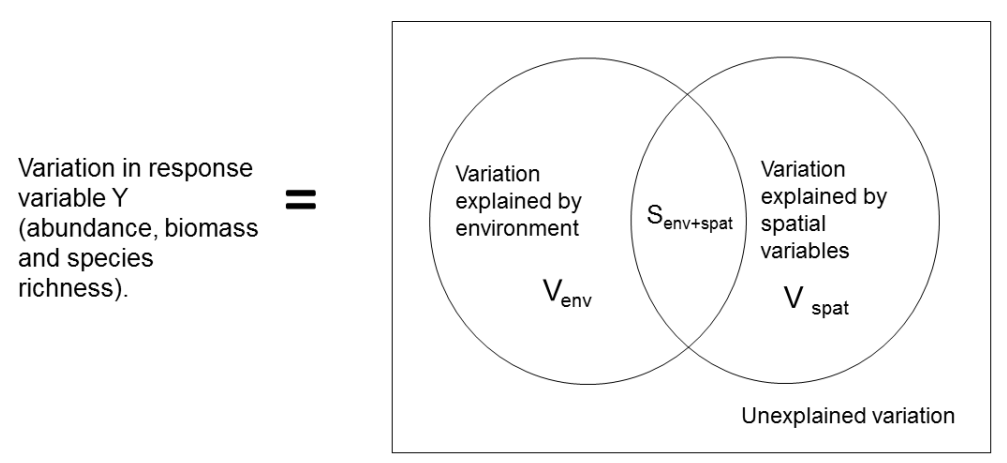

Figure 3. Venn diagram representing the partition of the variation of a response variable $Y$ (abundance, biomass and species richness) between two groups of explanatory variables (environmental and spatial). The rectangle represents $100 \%$ of the variation in Y (after Borcard et al., 2004).
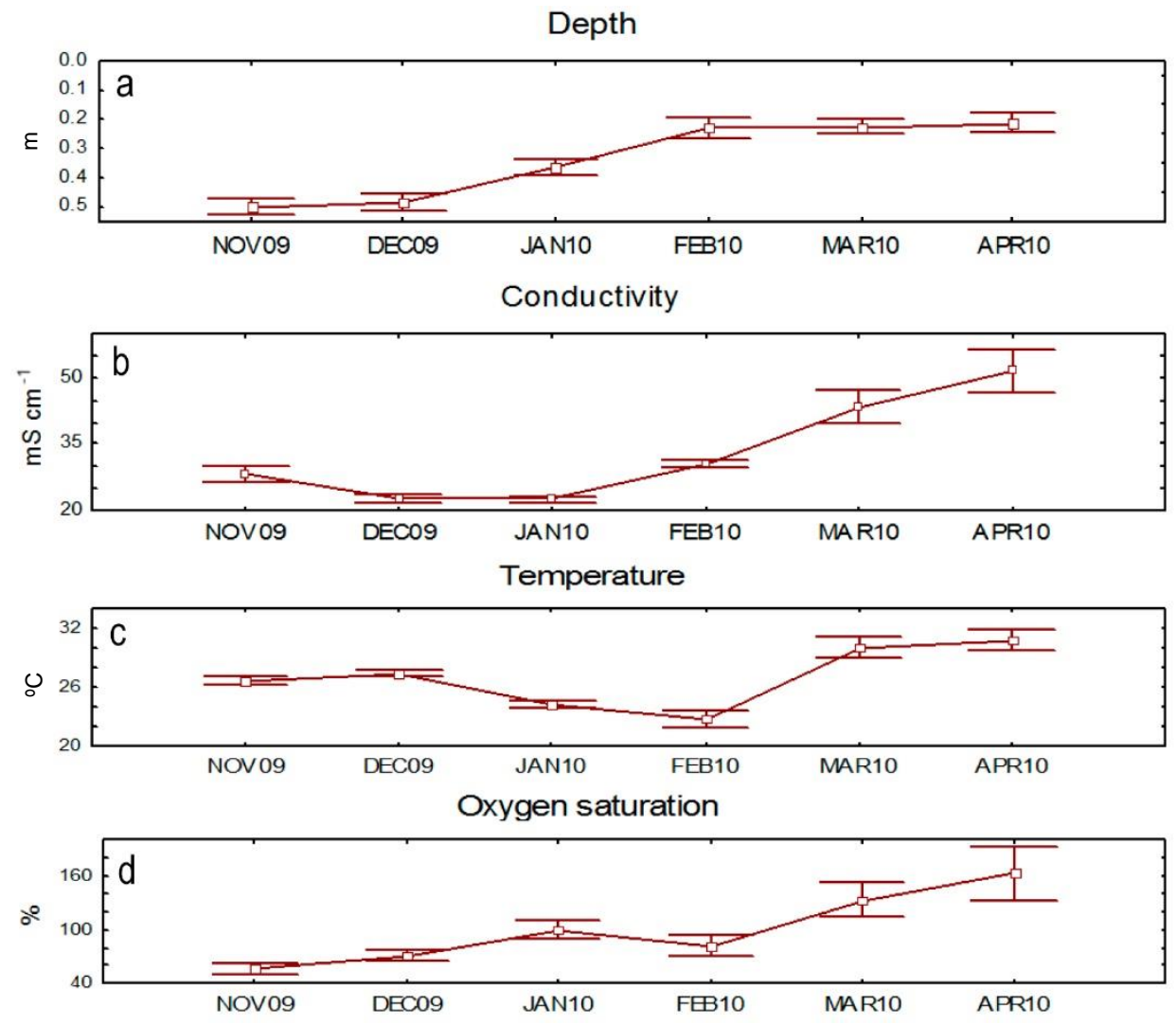

Figure 4. Values (mean \pm standard deviation) of the environmental variables over time: a) depth $(\mathrm{m})$, b) conductivity (mS $\left.\left.\mathrm{cm}^{-1}\right), \mathrm{c}\right)$ temperature $\left.\left({ }^{\circ} \mathrm{C}\right), \mathrm{d}\right)$ oxygen saturation $(\%)$.

with an average value of $51.5 \mathrm{mS} \mathrm{cm}{ }^{-1}$ (Fig. 4b). The averaged water temperature it was $26.9^{\circ} \mathrm{C}$, the lowest value was recorded in February with $22.7^{\circ} \mathrm{C}$. Values increased until they reached $30.6^{\circ} \mathrm{C}$ by the end of the study period in April (Fig. 4c). The percentage of oxygen saturation has an average of $100.5 \%$, with a tendency to increase over time, so when the study started in November was $56.2 \%$ and by the end in April 2010 recorded $162.7 \%$ saturation (Fig. 4d).
The 9,508 fish caught were from six species belonging to three families: Cyprinodontidae: the Yucatan pupfish Cyprinodon artifrons and the Yucatan flagfish Garmanella pulchra; Poeciliidae: the pike killifish Belonesox belizanus, the Yucatan gambusia Gambusia yucatana and sailfin molly Poecilia velifera; and Cichlidae: the Mayan cichlid Cichlasoma urophthalmus. The most abundant species was the endemic G. yucatana, representing $89.3 \%$ of the total abundance. 

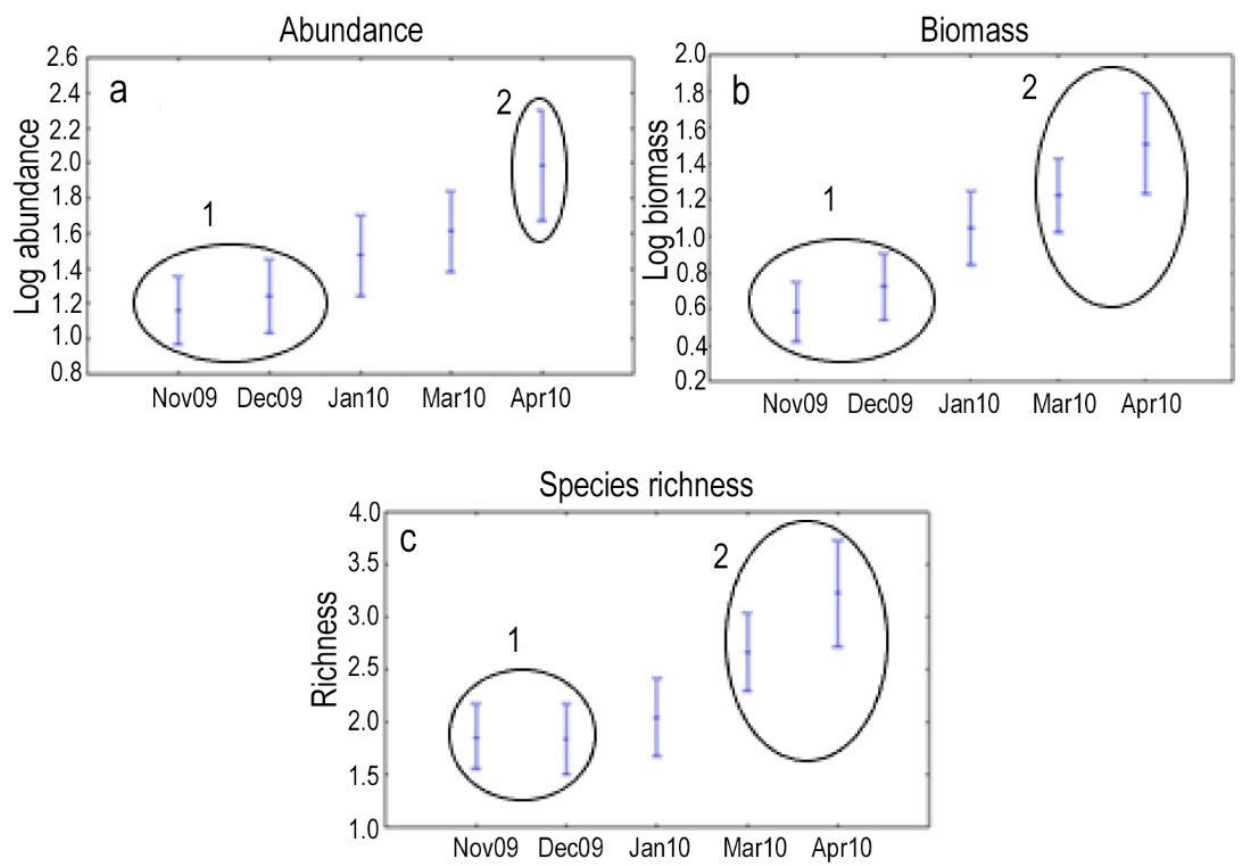

Figure 5. Structural characteristics of the fish community (abundance, biomass and species richness) by month. Groups 1 and 2 in each graph indicate significant differences over time (Tukey's HSD test; $P<0.05$ ).

Also, G. yucatana and $P$. velifera had the greatest contribution to the biomass values, with $72.4 \%$ and $14.9 \%$, respectively.

The fish community structure changed significantly over time. Abundance, biomass and species richness, formed at least two groups (post-hoc Tukey test) concerning time: one during the 'Nortes' season (November to February), and the other during the dry season (March to April) (Fig. 5). In February, no data were collected because of weather conditions.

\section{Environmental correlations}

Multiple regression results indicated significant relationships between community structure (abundance, biomass and species richness) and conductivity, depth, water temperature and oxygen saturation in most of the months (Table 1). The model relating biomass to conductivity obtained in March 2010 had the highest percentage of variance explained $\left(\mathrm{R}^{2}=0.41, \mathrm{Sr}^{2}=0.41\right.$, $P<0.001)$, followed by the one obtained between abundance and conductivity during December $2009\left(\mathrm{R}^{2}\right.$ $\left.=0.35, \mathrm{Sr}^{2}=0.35, P<0.1\right)$. The model relating species richness to oxygen saturation and temperature during March 2010 explained 32\% of the dependent variable. Still, oxygen saturation was better related to the community response than temperature according to the semi-partial correlation coefficients $\left(\mathrm{Sr}^{2}=0.12\right.$ and $\mathrm{Sr}^{2}$ $=0.10$, respectively $)($ Table 1$)$.
In most cases, conductivity was positively related to all response variables (abundance, biomass and species richness); the exception was for the biomass in March when a negative association was found. Relationships involving depth were consistently negative, indicating that abundance, biomass and diversity decrease as depth increases. Both variables (conductivity and depth) show a higher degree of association with abundance and biomass than with species richness (Table 1). Abundance was the variable least associated with the environmental variables. According to standardized regression coefficients, the environmental variables with the highest values of association with the community structure are, in order of importance, conductivity, oxygen saturation, depth and temperature (Table 1).

\section{Variance partitioning}

Variation in spatial (S) and environmental (E) factors and the combination of both (SE) effected the structure of the fish community (abundance, biomass and species richness), interacting with different intensity along time(Fig. 6). The variation in abundance was mainly influenced by the spatial variables (S) but also by combining the spatial and environmental variables (SE). The highest amount of explained variation in abundance was in March for spatial variables (S: 25.2\%) and in December for combined spatial and environmental 
Table 1. Regression standardized coefficients (B) and semi-partial correlations $\left(\mathrm{Sr}^{2}\right)$ for predicting abundance, biomass and species richness from environmental variables: conductivity $\left(\mathrm{mS} \mathrm{cm}^{-1}\right)$, depth $(\mathrm{m})$, temperature $\left({ }^{\circ} \mathrm{C}\right)$, Satox means oxygen saturation (\%), dissolved oxygen $\left(\mathrm{mg} \mathrm{L}^{-1}\right)$ and $\mathrm{pH}$ in a seasonally flooded karstic system in Yucatan, Mexico. $(\mathrm{n}=$ number of data; $\mathrm{R}^{2}=$ determination coefficient. Only the values of variables that were significant are shown). Variables included in the model with $* P<0.001, * * P<0.05, * * * P<0.1$.

\begin{tabular}{|c|c|c|c|c|c|c|c|c|c|c|c|c|c|c|c|}
\hline \multirow[t]{2}{*}{$\begin{array}{l}\text { Dependent } \\
\text { variable }\end{array}$} & \multirow[t]{2}{*}{$\begin{array}{l}\text { Model } \\
\text { parameters }\end{array}$} & \multicolumn{3}{|c|}{ Nov-09 } & \multicolumn{3}{|c|}{$\begin{array}{l}\text { Dec-09 } \\
(\mathrm{n}=30)\end{array}$} & \multicolumn{3}{|c|}{$\begin{array}{c}\text { Jan-10 } \\
(\mathrm{n}=24)\end{array}$} & \multicolumn{3}{|c|}{$\begin{array}{l}\text { Mar-10 } \\
(\mathrm{n}=24)\end{array}$} & \multicolumn{2}{|c|}{$\begin{array}{l}\text { Apr-10 } \\
(n=24)\end{array}$} \\
\hline & & B & $\mathrm{Sr}^{2}$ & $\mathrm{R}^{2}$ & B & $\mathrm{Sr}^{2}$ & $\mathrm{R}^{2}$ & B & $\mathrm{Sr}^{2}$ & $\mathrm{R}^{2}$ & B & $\mathrm{Sr}^{2}$ & $\mathrm{R}^{2}$ & B & $\begin{array}{ll}\mathrm{Sr}^{2} & \mathrm{R}^{2}\end{array}$ \\
\hline \multirow[t]{3}{*}{ Abundance } & & & & & & & 0.35 & & & 0.27 & & & & & \\
\hline & Conductivity & & & & $0.589 * * *$ & 0.35 & & & & & & & & & \\
\hline & Depth & & & & & & & $0.523^{* * *}$ & 0.27 & & & & & & \\
\hline \multirow[t]{4}{*}{ Biomass } & & & & 0.14 & & & 0.27 & & & 0.23 & & & 0.41 & & \\
\hline & Conductivity & & & & $0.523 * *$ & 0.27 & & & & & $-0.637 *$ & 0.41 & & & \\
\hline & Depth & & & & & & & $\begin{array}{c}- \\
0.478^{* * *}\end{array}$ & 0.23 & & & & & & \\
\hline & Oxygen saturation & $-0.38 * *$ & 0.14 & & & & & & & & & & & & \\
\hline \multirow{4}{*}{$\begin{array}{l}\text { Species } \\
\text { richness }\end{array}$} & & & & & & & 0.21 & & & 0.2 & & & 0.32 & & \\
\hline & Conductivity & & & & $0.459 * *$ & 0.21 & & & & & & & & & \\
\hline & Temperature & & & & & & & & & & $-0.404 * *$ & 0.1 & & & \\
\hline & Oxygen saturation & & & & & & & $0.442^{* *}$ & 0.2 & & $0.498 * *$ & 0.12 & & & \\
\hline
\end{tabular}

variables (SE: $30.3 \%$ ). In the case of biomass, variation was mainly influenced by the spatial variables $(S)$ and, to a less extent, the combination of variables (SE). The model best-explained biomass variation in December, when spatial variables explained $(26.8 \%)$ and the combination of variables (SE) explained $38.9 \%$. Finally, spatial and environ-mental variables provided the greatest explanation of variation in species richness in March (SE: 26.3\%; Fig. 6).

\section{DISCUSSION}

Despite the widely varying environmental conditions (E) in time, during the study, spatial variation (S) explained $49 \%$ of the total variation in fish community structure. In comparison, the shared variation of spatial and environmental variables (ES) explained $42 \%$, and the environmental variables alone explained $9 \%$. Thus, spatial variables appeared to be the main structuring force of the community, suggesting that the distribution and abundance of each population depend to a greater extent on their dispersal mechanisms and reproductive strategies than on distribution constraints imposed by environmental factors (Jones et al., 2008).

Species with high dispersal ability often display opportunistic reproductive strategies, characterized by the production of many small offspring (Winemiller \& Rose, 1992). The most abundant and widely distributed species in the study area was Gambusia yucatana ( $89.3 \%$ of relative abundance), which may be charac- terized as an opportunistic species (Greenfield et al., 1983; Vázquez-Domínguez et al., 2009). Its viviparous reproduction is quite effective in systems where environmental variables are highly fluctuating (as is the case here). Since its initial development takes place inside the mother and away from exposure to environmental changes inside their mother, also less susceptible to predation compared to being out in the open during its most vulnerable stages, this ensures a high early survival (Greenfield \& Thomerson, 1997). The viviparous neonates may be more resistant to strong environmental variation compared to oviparous fish's larvae (Trexler et al., 2011). Also, the gradual increase of the extension of the water body, at the start of the rainy season, provides a temporary advantage to the species with the high dispersal rates. A rapid colonizer, like $G$. yucatana, can populate newly available habitats before being subjected to competition that takes place when other successful species arrive to colonize the area (De Angelis et al., 2005).

The extent and speed with which the temporary areas are flooded are important factors for the analysis of some attributes of the fish community, especially small species that move from permanent wetlands, such as swamps and canals, towards the temporary systems as they become flooded (Kushlan et al., 1975; Goss et al., 2014). Their population and biomass quickly increase during the re-flooding period, and they can follow the front of the flood at displacement rates approximately equal to the speed of the front, with the population expanding so rapidly that it produces much 

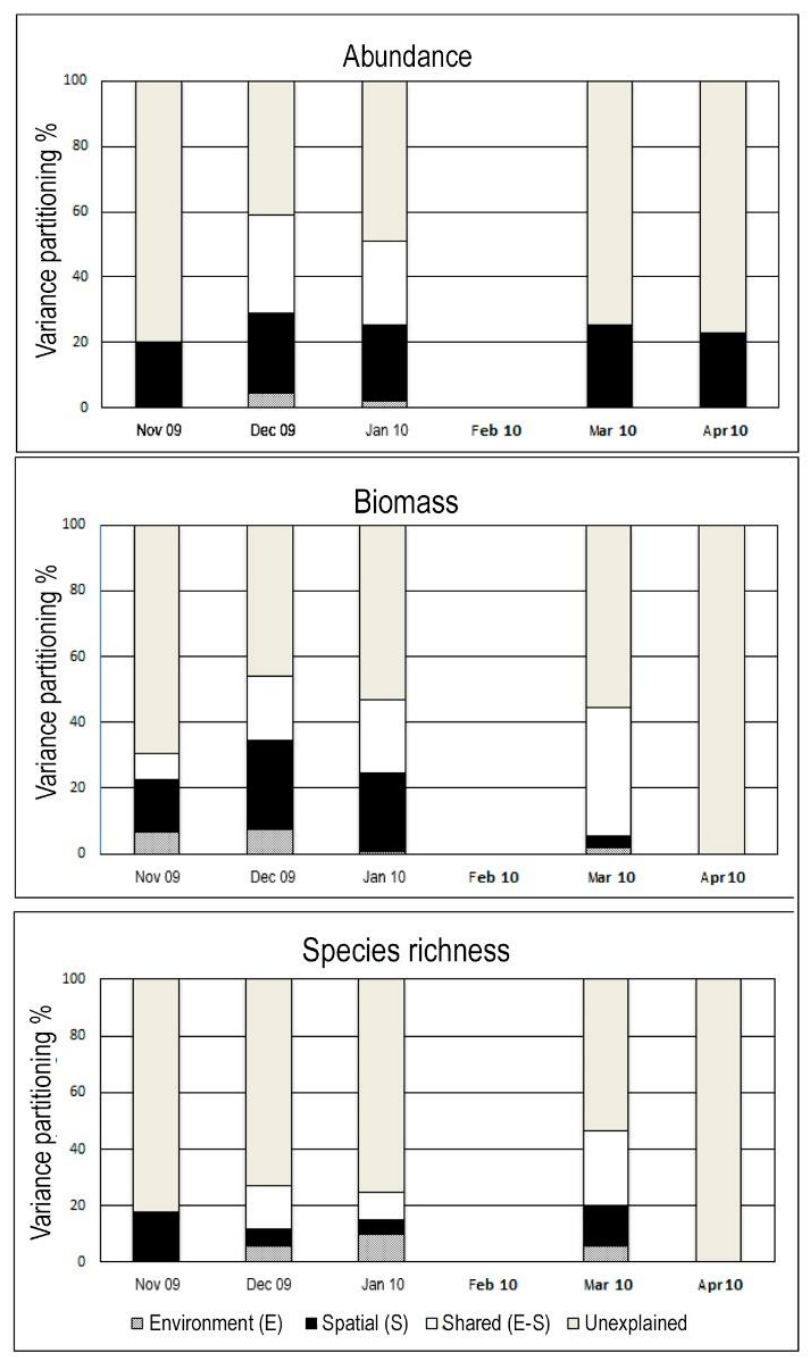

Figure 6. Partitioning of the variation using the spatial factors (S), environmental factors (E), and the shared variability (E-S). No data in February.

of the new biomass during the rainy season (Trexler et al., 2001; Gawlik, 2002; Russell et al., 2002). This capability is the key to ensure the success of species with abilities of rapid colonization, moving fast in lowdepth waters, and giving an advantage over other species to extend its range rapidly from permanent shelters to the full extent of the temporary system as the flood starts (De Angelis et al., 2010; Hoch et al., 2015).

Studies in the Everglades reported that small fish survived and then tended to congregate in small water bodies when the water levels fell during the dry season so that the fish biomass was available to animals at higher trophic levels (Loftus \& Kushlan, 1987; Trexler et al., 2001). Since the El Palmar reserve characteristics are similar to those of the Everglades, the existence here also of these permanent refuges is very likely. By providing 'seeds', they facilitate the dispersal in the flood season that benefits small species in the area, such as G. yucatana and Cyprinodon artifrons, the species smallest in size found in this reserve with a reported maximum length of $40 \mathrm{~mm}$ in each case. Cichlasoma urophthalmus is a species with high dispersal ability, and it is capable of traveling long distances between natural and artificial systems in the Everglades in Florida (Parkos \& Trexler, 2014).

Loftus et al. (1992) proposed that small pools and solution holes reaching the aquifer typical of karstic wetlands create refuges that maintain small populations of little fish around the landscape through the dry season (Loftus et al., 1992). Capone \& Kushlan (1991) suggested that small fish are at an advantage in droughtprone systems because small individuals have greater access to hydrological refuges. When water levels gradually rise again along an altitudinal gradient, small populations in those refuge pools can provide 'seeds' for the growth of the population as soon as an area is flooded. The possible importance of such fish refuges has been recognized in the Everglades (Gaff et al., 2000), in an intermittent lowland stream in Australia (Perry \& Bond, 2009), and an intermittent stream in Costa Rica (Chapman et al., 1991). The fish species found in the coastal wetlands of the northern coast of the Yucatan Peninsula are precisely those that can tolerate the changing environmental conditions modified by the dynamics imposed by the space. Although the conditions are extremely variable in space and time, the fish species that use the wetland system have developed adaptations to cope. There are similar systems in estuaries, where the species are adapted to cope with extreme changes in salinity. The species that use these systems do not necessarily experience these conditions as extreme.

In this study, the environmental variables with influence throughout time over the structure of the fish community were, in order of importance, conductivity, oxygen saturation, tempe-rature and depth of the studied area. Studies developed in similar systems have found that the environmental variables regulating variation in the fish community structure are pool depth, pool persistence and $\mathrm{pH}$ (Capone \& Kushlan, 1991); depth, size of the system, oxygen concentration and habitat heterogeneity (Magoulick, 2000); temperature, depth, $\mathrm{pH}$ and macrophyte coverage (Escalera-Vázquez \& Zambrano, 2010). In the same study, it was proposed that for most species, an important part of the spatial and temporal variation can be explained as an effect of the dry season (EscaleraVázquez \& Zambrano, 2010). Wellborn et al. (1996) proposed that dry seasons can change community structure by acting as an environmental filter and eliminating species that cannot survive the harsh 
conditions. Therefore, dry seasons can reduce the variability of fish communities among sites (pools) that have similar hydroperiod (Chase, 2007).

Some of our environmental variables were correlated, making it impossible to separate their effects. For example, despite having been considered as an environmental variable related to climate conditions, the temperature is closely linked to water depth. The highly seasonal rainfall pattern of the region that includes the El Palmar State Reserve creates a cycle of wet and dry seasons, causing marked contrasts in the environmental conditions within the seasonally flooded area in the coastal strip (Sanderson et al., 2005).

Owing to the flat landscape, relatively small differences in the mean sea level can make significant differences in the surface area and duration of flooding, and this many effect plant species and animal communities. The fish community, mainly the small fishes of the wetland, is strongly influenced by the seasonal hydrological variation that is a feature of many wetlands (Loftus \& Kushlan, 1987; Trexler et al., 2001; Mitsch \& Gosselink, 2007).

To conclude, variation in fish community structure in a seasonally flooded karst system primarily depend on the spatial variables, which means that the main limitation in the distribution and abundance of the fish community is its ability to disperse in the aquatic ecosystem. Although the variation of spatial factors had the greatest influence on the fish community, there was also an effect of the environmental variables conductivity, oxygen saturation, temperature and depth. At various times throughout the study, there was a more significant influence from the variable combination than from either the spatial or environmental variables alone. This variation and changes over time demonstrate the considerable dynamism of these types of system studies.

Future work should include measures related to biological interactions such as competition and predation because they may regulate the fish community structure in seasonally flooded karst environments. Also, an evaluation of resource availability (e.g., food, shelter) and mobility/residency of the species studied. However, it is also necessary to conduct monitoring in several periods of flooding, to assess whether the community is modified by the intensity and frequency of drought as suggested Trexler et al. (2005), confirming that the community may be structured primarily by dispersal.

Coastal wetlands are home to diverse communities of aquatic animals that support essential communities of apex predators. Conservation of these ecosystems and maintenance of their hydrological drivers is challenging as human populations continue to encroach on coastal zones. Efforts to better understand how hydrological function is linked to aquatic animal concentration will benefit efforts to conserve the wildlife values they support.

\section{ACKNOWLEDGMENTS}

This investigation was financed by research grants by PAPIIT (IN213012 \& IN219515), PAPIME (PE204012), PROMEP (103.5/12/2122), and FOMIXYucatan (103 229). We thank Carmen Galindo for her statistical advice and Joel Trexler for editorial advice. Maribel Badillo, Alfredo Gallardo and Korynthia López for their technical support during different phases of the research. JLP is grateful to CONACyT (México) for the scholarship awarded to pursue doctoral studies in the Posgrado en Ciencias del Mar y Limnología, UNAM.

\section{REFERENCES}

Alexander, H.M., Foster, B.L., Ballantyne IV, F., Collins, C.D., Antonovics, J. \& Holt, R.D. 2012. Metapopulations and metacommunities: combining spatial and temporal perspectives in plant ecology. Journal of Ecology, 100: 88-103.

Baber, M.J., Childers, D.L., Babbitt, K.J. \& Anderson, D.H. 2002. Controls on fish distribution and abundance in temporary wetlands. Canadian Journal of Fisheries and Aquatic Sciences, 59: 1-10.

Borcard, D. \& Legendre, P. 2002. All-scale spatial analysis of ecological data by means of principal coordinates of neighbor matrices. Ecological Modelling, 153: 51-68.

Borcard, D., Legendre, P., Avois-Jacquet, C. \& Tuomisto, H. 2004. Dissecting the spatial structure of ecological data at multiple scales. Ecology, 85(7): 1826-1832.

Capone, T.A. \& Kushlan, J.A. 1991. Fish community structure in dry-season stream pools. Ecology. 72: 983-992.

Carr, M. \& Syms, C. 2006. Recruitment. In: Allen, L.G., Pondella, D.J. \& Horn, M.H. (Eds.). The ecology of marine fishes: California and adjacent waters. University of California Press, Berkeley.

Chapman, L.J., Kramer, D.L. \& Chapman, C.A. 1991. Population dynamics of the fish Poecilia gillii (Poeciliidae) in pools of an intermittent tropical stream. Journal of Animal Ecology, 60: 441-453.

Chase, J.M. 2007. Drought mediates the importance of stochastic community assembly. Proceedings of the National Academy of Sciences, 44: 17430-17434. 
Choat, J.H. \& Bellwood, D.R. 1985. Interactions among herbivores fish on a coral reef: influence of spatial variation. Marine Biology, 89: 221-231.

Condit, R., Pitman N., Leight, E.J., Chave, J., Terborgh, J., Foster, R.B., et al. 2002. Beta-diversity in tropical forest trees. Science, 295: 666-669.

Cottenie, K. 2005. Integrating environmental and spatial processes in ecological community dynamics. Ecology Letters, 8: 1175-1182.

De Angelis, D.L., Trexler, J.C. \& Loftus, W.F. 2005. Lifehistory trade-offs and community dynamics of small fishes in a seasonally pulsed wetland. Canadian Journal of Fishery and Aquatic Sciences, 62: 781-790.

De Angelis, D.L., Trexler, J.C., Cosner, C., Obaza, A. \& Jopp, F. 2010. Fish population dynamics in a seasonally varying wetland. Ecological Modelling, 221: 1131-1137.

Doherty, P.J. 1991. Spatial and temporal patterns in recruitment. In: Sale, P.F. (Ed.). The ecology of fishes on coral reef. Springer, Berlin.

Dray, S., Legendre, P. \& Peres-Neto, P.R. 2006. Spatial modeling: a comprehensive framework for the principal coordinate analysis of neighbor matrices (PCNM). Ecological Modelling, 196: 483-493.

Escalera-Vázquez, L. \& Zambrano, L. 2010. The effect of seasonal variation in abiotic factors on fish community structure in temporary and permanent pools in a tropical wetland. Freshwater Biology, 55(12): 25572569. doi: 10.1111/j.1365-2427.2010.02486.x

Fourqurean, J.W. \& Rutten, L.M. 2003. Competing goals of spatial and temporal resolution: monitoring seagrass communities on a regional scale. In: Busch, D.E. \& Trexler, J.C. (Eds.). Monitoring ecosystems. Interdisciplinary approaches for evaluating ecoregional initiatives. Island Press, Washington, D.C., pp. 257-288.

Gaff, H., De Angelis, D.L., Gross, L.J., Salinas, R. \& Shorrosh, M. 2000. A dynamics landscape model for fish in the Everglades and its application to restoration. Ecological Modelling, 127: 33-52.

Gaiser, E., Gottlieb, A., Lee, S. \& Trexler, J.C. 2015. The importance of species-based microbial assessment of water quality in freshwater Everglades wetlands. In: Entry, J.A., Gottlieb, A.D., Jayachandrahan, K. \& Ogram, A. (Eds.). Microbiology of the Everglades ecosystem. CRC Press, Florida, pp. 115-130.

Gallardo-Torres, A., Badillo-Alemán, M., Rivera-Félix, V., Rubio-Molina, J., Galindo De Santiago, C., LoeraPérez, J., García-Galano, T. \& Chiappa-Carrara, X. 2014. Catálogo de peces de la costa norte de Yucatán. Universidad Nacional Autónoma de México, Ciudad de México.

Gawlik, D.E. 2002. The effects of prey availability on the numerical response of wading birds. Ecological Monographs, 72: 329-346.
Goss, C.W., Loftus, W.F. \& Trexler, J.C. 2014. Fish colonization of ephemeral wetlands in the Florida Everglades. Wetlands, 34: 147-157.

Greenfield, D.W. \& Thomerson, J.E. 1997. Fishes of the continental waters of Belize. University Press, Florida.

Greenfield, D.W., Greenfield, T.A. \& Brinton, S.L. 1983. Spatial and trophic interactions between Gambusia sexradiata and Gambusia puncticulata yucatana (Pisces, Poeciliidae) in Belize, Central America. Copeia, 1983: 598-607.

Hoch, J.M., Sokol, E.R., Parker, A.D. \& Trexler, J.C. 2015. Migrations strategies vary in space, time, and among species in the small-fish metacommunity of the Everglades. Copeia, 103: 157-169.

Hutchinson, G.E. 1957. Concluding remarks. Cold Spring Harbor Symposia on Quantitative Biology, 22: 415427.

Jones, M.M., Tuomisto, H., Borcard, D., Legendre, P., Clark, D.B. \& Olivas, P.C. 2008. Explaining variation in tropical plant community composition: influence of environmental and spatial data quality. Oecologia, 155: 593-604.

Kobza, R.M., Trexler, J.C., Loftus, W.F. \& Perry, S.A. 2004. Community structure of fishes inhabiting aquatic refuges in a threatened Karst wetland and its implications for ecosystem management. Biological Conservation, 116: 153-165.

Kushlan, J.A., Ogden, J.C. \& Higer, A.L. 1975. Relation of water level and fish availability to wood stork reproduction in the southern Everglades, Florida. U.S. Geological Survey, Tallahassee.

Lace, M.J. \& Mylroie, J.E. 2013. Coastal karst landformes. Springer, New York.

Leibold, M.A. 2008. Ecology: return of the niche. Nature, 454: 39-41.

Legendre, P. 1993. Spatial autocorrelation: trouble or new paradigm? Ecology, 74: 1659-1673.

Legendre, P. \& Fortin, M.J. 1989. Spatial pattern and ecological analysis. Vegetatio, 80: 107-138.

Loftus, W.F. \& Kushlan, J.A. 1987. Freshwater fishes of southern Florida. Biological Sciences, 31: 147-344.

Loftus, W.F., Johnson, R.A. \& Anderson, G.H. 1992. Ecological impacts of the reduction of groundwater levels in short-hydroperiod marshes of the Everglades. In: Stanford, J.A. \& Simons, J.J. (Eds.). Proceedings of the First International Conference on Ground Water Ecology. American Water Resources Association, pp. 199-208.

López-Martínez, J.O., Hernández-Stefanoni, J.L., Dupuy, J.M. \& Meave, J.A. 2013. Partitioning the variation of woody plant b-diversity in a landscape of secondary tropical dry forests across spatial scales. Journal of Vegetation Science, 24: 33-45. 
Magoulick, D.D. 2000. Spatial and temporal variation in fish assemblages of drying stream pools: the role of abiotic and biotic factors. Aquatic Ecology, 34: 29-41.

Menge, B.A., Gouhier, T.C., Freudenburg, T. \& Lubchenco, J. 2011. Linking long-term, large-scale climatic and environmental variability to patterns of marine invertebrate recruitment: toward explaining "unexplained" variation. Journal of Experimental Marine Biology and Ecology, 400: 236-249.

Mitsch, W.J. \& Gosselink, J.G. 2007. Wetlands. John Wiley \& Sons, New Jersey.

Morlon, H., Chuyong, G., Condit, R., Hubbell, S.P., Kenfack, D. \& Thomas, D. 2008. A general framework for the distance-decay of similarity in ecological communities. Ecology Letters, 11: 904-917.

Núñez-Lara, E., González-Salas, C.F. \& Arias-González, J.E. 2012. Comunidades de peces de los arrecifes de cayo Arcas y Triángulos en el banco de Campeche: separación de la variación espacial y ambiental. In: Sánchez, J.A., Chiappa-Carrara, X. \& Brito-Pérez, R. (Eds.). Recursos acuáticos costeros del sureste. Red para el Conocimiento de los Recursos Costeros del Sureste, Ciudad de México, pp. 69-90.

Obaza, A., De Angelis, D.L. \& Trexler, J.C. 2011. Using data from an encounter sampler to model fish dispersal. Journal of Fish Biology, 78: 495-513.

Ortega-Mayagoitia, E., Rojo, C. \& Rodrigo, M.A. 2002. Factors masking the trophic cascade in shallow eutrophic wetlands: evidence from a microcosm study. Archiv fur Hydrobiologie, 155: 43-63.

Parkos, J.J. \& Trexler, J.C. 2014. Origins of functional connectivity in a human-modified wetland landscape. Canadian Journal of Fisheries and Aquatic Sciences, 71: 1-12. doi: 10.1139/cjfas-2013-0553

Perry, G.L. \& Bond, N.B. 2009. Spatially explicit modeling of habitat dynamics and fish population persistence in an intermittent lowland stream. Ecological Applications, 19: 731-746.

Ruetz, C.R., Trexler, J.C., Jordan, F., Loftus, W.F. \& Perry, S.A. 2005. Population dynamics of wetland fishes: spatio-temporal patterns synchronized by hydrological disturbance? Journal of Animal Ecology, 74: 322-332.

Russell, G.J., Bass, O.L. \& Pimm, S.L. 2002. The effect of hydrological patterns and breeding-season flooding on the numbers and distribution of wading birds in Everglades National Park. Animal Conservation, 5: 185-199.

Sale, P.F. 1980. The ecology of fishes on coral reefs. Oceanography and Marine Biology Annual Review, 18: 367-421.

Sale, P.F. \& Douglas, W.A. 1984. Choice of microhabitats by coral reef fishes at settlement. Coral Reefs, 1: 9199 .
Sanderson, R.A., Eyre, M.D. \& Rushton, S.P. 2005. Distribution of selected macroinvertebrates in a mosaic of temporary and permanent freshwater ponds, as explained by autologistic models. Ecography, 28: 355-362.

Schmitter-Soto, J.J. 1998. Catálogo de los peces continentales de Quintana Roo. Ecosur, Quintana Roo.

Schwartz, S.S. \& Jenkins, D.C. 2000. Temporary aquatic habitats: constraints and opportunities. Aquatic Ecology, 34: 3-8.

Soto-Ortiz, L. 2015. The regulation of ecological communities through feedback loops: a review. Research in Zoology, 5(1): 1-15.

Trexler, J.C., De Angelis, D.L. \& Jiang, J. 2011. Community assembly and mode of reproduction: predicting the distribution of livebearing fishes, In: Evans, J., Pilastro, A. \& Schlupp, I. (Eds.). Ecology and evolution of Poeciliid fishes. University of Chicago Press, Chicago, pp. 95-108.

Trexler, J.C., Loftus, W.F. \& Perry, S. 2005. Disturbance frequency and community structure in a twenty-five year intervention study. Oecologia, 145: 140-152.

Trexler, J.C., Loftus, W.F., Jordan, F., Chick, J.H., Kandl, K.L., McElroy, T.C. \& Bass Jr., O.L. 2001. Ecological scale and its implications for freshwater fishes in the Florida Everglades. In: Porter, J.W. \& Porte, K.G. (Eds.). The Everglades, Florida Bay, and coral reefs of the Florida Keys: an ecosystem sourcebook. CRC Press, Florida, pp. 153-181.

Tuomisto, H., Ruokolainen, K. \& Yli-Halla, M. 2003. Dispersal, environment, and floristic variation of western Amazonian forests. Science, 241: 241-244.

Universidad Autónoma de Yucatán (UADY). 1999. Atlas de procesos territoriales de Yucatán. Universidad Autónoma de Yucatán, Yucatán.

Vázquez-Domínguez, E., Hernández-Valdés, A., RojasSantoyo, A. \& Zambrano, L. 2009. Contrasting genetic structure in two codistributed freshwater fish species of highly seasonal systems. Revista Mexicana de Biodiversidad, 80: 181-192.

Vega-Cendejas, M.E. 2005. Evaluación de la ictiofauna en las áreas focales del corredor biológico costeroYucatán. Informe Final SNIB-CONABIO, No. Y027. Instituto Politécnico Nacional, Ciudad de México.

Waltho, N.D. \& Kolasa, J. 1996. Stochastic determinants of assemblage patterns in coral reef fishes: a quantification by means of two models. Environmental Biology of Fishes, 47: 255-267.

Wellborn, G.A., Skelly, D.K. \& Werner, E.E. 1996. Mechanisms creating community structure across a freshwater habitat gradient. Annual Review of Ecology, Evolution and Systematics, 27: 337-363. 
Winemiller, K.O. \& Rose, K.A. 1992. Patterns of lifehistory diversification in North American fishes: implications for population regulation. Canadian Journal of Fisheries and Aquatic Sciences, 49: 21962218.

Received: 13 August 2019; Accepted: 10 December 2019
Zar, J.H. 1999. Biostatistical analysis. Prentice-Hall, New Jersey. 